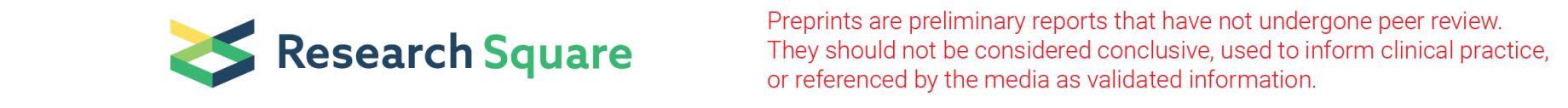

\title{
Screening of prognostic biomarkers for Stereotactic Body Radiation Therapy in liver cancer
}

\author{
Zhenzhen Liang \\ Jilin University \\ Hongbin Sun \\ Jilin University \\ Binbin Yu \\ Jilin University \\ Xueyuan Zhang \\ Jilin University \\ Xinxin Fu \\ Wenzhou Medical University \\ Heya Jiang \\ Wenzhou Medical University \\ Lianchang Liu \\ Jilin University
}

Xiaodong Liu (D liuxd2014@126.com )

School of Public Health and Management,Wenzhou Medical University,Wenzhou,Zhejiang 325035 https://orcid.org/0000-0002-6879-990X

\section{Research article}

Keywords: SBRT, liver cancer, prognosis, biomarkers

Posted Date: February 13th, 2020

DOI: https://doi.org/10.21203/rs.2.23507/v1

License: @ (1) This work is licensed under a Creative Commons Attribution 4.0 International License. Read Full License 


\section{Abstract}

So far there are still no effective immediate-early markers for assessing the efficacy of Stereotactic Body Radiation Therapy (SBRT). To find effective biomarkers for accurate assessment of the efficacy of SBRT in patients with liver cancer. Patients with liver cancer were included at Ruikang Hospital affiliated to Guangxi Medical University from January 2012 to December 2018. Follow-up was conducted, clinical information and blood samples (before SBRT, before discharge and 2 months after SBRT) were collected. mRNAs profiles were detected by high-throughput sequencing, followed by qPCR verification. The commonly-used serum biomarkers such as AFP, CEA and CA125 shown low prognostic value in distinguishing survival group and death group, indicated by low AUC (less than 0.7) and Yoden indexes (less than 0.5). Based on high-throughput sequencing of test group and qPCR detection of another verification group, we found 16 up-regulated and 12 down-regulated genes after SBRT. Among them, ADIPOR1 and EPB42 showed significantly different between effective and ineffective group after SBRT, ROC suggested that based on the optimal threshold of 0.5838 , ADIPOR1 shown a sensitivity of $100 \%$ and a specificity of $83.33 \%$ to distinguish effective from ineffective group. Similarly, EPB42 had a sensitivity of $75 \%$ and a specificity of $100 \%$ at the optimal threshold of 1.3817 . Thus, ADIPOR1 and EPB42 in whole blood are promising candidates to act as prognostic biomarkers for predication of SBRT outcomes in liver cancer patients.

\section{Introduction}

Liver cancer is expected to be the sixth most frequently diagnosed cancer and the fourth leading cause of cancer death around the world in 2018, with 841,000 new cases and 782,000 deaths per year[1]. It is also one of the most common malignant tumors in China, showing No. 4 of morbidity and No. 2 of mortality among malignant tumors in Chinese[2]. The main risk factors for liver cancer are chronic hepatitis B virus (HBV) or hepatitis $\mathrm{C}$ virus $(\mathrm{HCV})$, heavy alcohol intake, aflatoxin-contaminated foods, obesity, smoking, etc. Among all cancers in China, liver cancer has the poorest survival and the age-standardized 5-year relative survival is only $10.1 \%[3]$. Invasion, metastasis and recurrence are the primary factors that affect clinical treatment and prognosis[4]. Besides, the insidious onset of liver cancer is another reason, for the majority of liver cancer patients are diagnosed at a late stage when it is too far advanced to be cured[5]. Being highly malignant with rapid progression, the treatment for advanced liver cancer is difficult.

At present, there are various treatment methods for liver cancer, including surgical treatment, such as radical surgical resection and liver transplantation; non-surgical treatment, such as local ablation therapy, arterial chemoembolization, gene molecular targeted therapy, systemic chemotherapy, radiotherapy and et[6]. Surgical resection has proven to be the optimal treatment for long-term survival of liver cancer patients[7]. However, more than $70 \%$ of patients with liver cancer are unable to undergo liver resection due to the location, size, number of liver tumors, and impaired liver function. Therefore, the status of non-surgical therapy in the treatment of liver cancer is self-evident. For patients with liver cancer who are unable to undergo surgery, the National Comprehensive Cancer Network Clinical Practice Guidelines in Oncology (NCCN guidelines) recommend radiation therapy as one of the treatments[8].

With the rapid development of computer, radiotherapy and imaging technology, precise radiotherapy has become possible. Beginning with the three-dimensional conformal radiation therapy, radiation therapy is increasingly being used for the treatment of liver cancer. At present, radiotherapy for liver cancer includes a series of advanced technologies, such as intensity-modulated radiation therapy, body stereotactic radiotherapy, and particle therapy. Current precision external exposure techniques ensure that the tumor is locally administered with high doses while protecting the remaining normal liver tissue from exposure to low doses, thereby limiting the risk of radiation-induced liver damage. In addition, external beam radiation therapy (EBRT) is applied to tumors in almost all locations of the liver. Stereotactic Body Radiosurgery (SBRT) is an advanced technique of EBRT that delivers large ablative doses of radiation. Increasing evidence supported the usefulness of SBRT for patients with unresectable, locally advanced, or recurrent liver cancer[9-11]. Additionally, NCCN also recommends that SBRT can also be used as an alternative to ablation/TACE treatments, options for treatment after ablation/ TACE failure, or treatment options for liver cancer patients with ablation/ TACE contraindications.

However, to date, the evaluation of radiotherapy efficacy relies mainly on imaging data and the calculated local control based on complete response (CR), partial response (PR), stable disease (SD), progressive disease (PD), such long-term index as overall survival (OS), disease-free survival (DFS), progression-free survival (PFS), etc are also used. In addition, some serum molecules have been used for diagnostic marker, for example, AFP has long been used for diagnosis of liver cancer, but even in the advanced stage 15-30\% of patients with a normal AFP levels[12]. So far there are still no effective immediate-early markers for assessing the efficacy of radiotherapy. Therefore, finding biomarkers with prognostic value for radiotherapy is still a focus that researchers are paying attention to. Genetics affects the occurrence and development of tumors, whether the change of mRNA profiles in venous blood after radiotherapy could be used as prognostic biomarkers, is our concern, this is the first report for searching prognostic biomarkers for liver patients treated by SBRT.

\section{Material And Methods}

\section{Patient selection and medical record collection}


The liver cancer patients involved in this study were divided into two parts. In the retrospective study, the clinical records of all liver cancer patients who underwent SBRT at Ruikang Hospital affiliated to Guangxi Medical University from January 2012 to December 2018 were retrospectively reviewed and follow-up was conducted in the following years. In the prospective study, we collected blood samples from liver cancer patients who received SBRT from December 2017 to December 2018. Three blood samples for each patient were collected, i.e., before SBRT, before discharge and 2 months after SBRT. In addition, the inclusion criteria are as follows: 1 . Size less than $10 \mathrm{~cm}$, with Child A or B liver function; 2 . First treatment without previous treatment history, 80Gy < BED < 100Gy (BED: Biologically Effective Dose); 3. No other comprehensive treatment such as chemotherapy that seriously affects the blood index. Patients were all informed of the study and signed a written informed consent form. All patients provided informed written consent and all research and related activities involving human subjects were approved by the Ethics Committee of the 1 st and 2nd hospital affiliated to Jilin University and performed in accordance with guidelines and regulations and the Declaration of Helsinki. Trial registration: ResMan, number: ChiCTR1800015499. Registered 20 April 2018, www.medresman.org

\section{Specimen collection and High-throughput sequencing}

In this study, Paxgene Blood RNA Tubes (PreAnalytiX, Qiagen BD, Valencia, CA) (abbreviated as BRT) were used to collect blood samples for quick protection of the RNA from degradation. PAXgene Blood RNA Kit (PreAnalytiX, Qiagen BD, Valencia, CA) was used for subsequent experimental studies. The whole blood samples $(5 \mathrm{~mL})$ were transported to Novogene (Novogene, Beijing) for RNA isolation, quality control, library preparation and sequencing.

\section{Quantification of mRNAs by RT-qPCR analysis}

Blood samples were collected before SBRT (first sample), before discharge (second sample) and 2 months after SBRT (third sample), for a total of 51 samples. Blood sample collection and RNA extraction were all carried as previously described. For the reverse transcription reaction, the RT reaction solution was prepared on ice according to the following components: $2 \mu$ of $5 \times$ PrimeScript RT Master Mix (Perfect Real Time), 500 ng of total RNA, followed by RNase Free $\mathrm{dH} 2 \mathrm{O}$ up to $10 \mu$ l. The reaction mixtures were incubated at $37^{\circ} \mathrm{C}$ for 15 min, followed by $85^{\circ} \mathrm{C}$ for 5 sec and saved at $4^{\circ} \mathrm{C}$. qRT-PCR was performed using the ABI StepOnePlus ${ }^{T M}$ Real-Time PCR System (Applied Biosystems, Foster City, CA).

All primer set were designed and synthesized by Wcgene Biotechnology Corporation (Shanghai, China). The sense and antisense primers of ADIPOR1 are: TCCTGCCAGTAACAGGGAAG and GGTTGGCGATTACCCGTTTG; the sense and antisense primers of EPB42 are: ACTTGTTGAA CCAGAATGGT CTC and TCCACTTCTC TACCTGCTTG TC; and so on. GAPDH (forward primers: CAATGACCCC TTCATTGACC and reverse primers: GACAAGCTTC CCGTTCTCAG) was used as the reference control. We used the TB Green ${ }^{\text {TM }}$ Premix Ex TaqTM II (Tli RNaseH Plus) (Takara, Code No. RR820A) as the QPCR test kit following the manufacturer's recommendations. The $2^{-\Delta \Delta C t}$ method was performed to calculate the relative levels of mRNAs.

\section{Statistical analysis}

Nonparametric test and Student's t test were used to compare differences between two groups. Area under receiver-operating characteristic (ROC) curve (AUC) was used to determine the optimal cut-off value of blood mRNA levels and their diagnostic ability. $P$-values (in two-sided tests) $\leq 0.05$ were considered statistically significant. Histograms were plotted by Graphpad Prism 7.0 (San Diego, California). Heatmap was drawn by the pheatmap package within R package version 3.5.1. Statistical analyses were performed using SPSS, version 24 (IBM Corp., Armonk, NY, USA). In addition, Medcalc software, version 11.5.0.0 (MedCalc Software, Mariakerke, Belgium) was used to evaluate the prognostic value of biomarkers. All authors had access to the study data and had reviewed and approved the final manuscript.

\section{Results}

\section{Patient specimens}

In the retrospective study, we collected a total of 589 liver cancer patients admitted to hospital for SBRT between January 2012 and December 2018. After excluding 55 patients who were lost for follow-up, a total of 534 patients were involved in the following research. In the prospective study, 51 samples were collected, the outcome after SBRT were followed up and recorded, the relationship between markers and prognosis, the $\mathrm{ROC}$ and assessment of prognostic value were analyzed.

\section{Prognostic analysis of commonly-used serum tumor biomarkers}

Cancer biomarkers, such as AFP, CEA, CA199, CA153, CA125, are commonly used for diagnosis. By detecting the levels of these biomarkers, clinician can make a preliminary assessment of the occurrence and progress of tumors. Jung $\mathrm{J}$ et al.[13] reported that liver cancer patients had a better prognosis when AFP levels returned to normal levels 3 months after SBRT, Uemotok et al.[14] found that the risk of recurrence was associated with the elevated AFP level. Whether those biomarkers are with prognostic value is our concern. In this study, we selected patients together with serum biomarker examination before SBRT, 3 months after SBRT, and 6 months after SBRT. The results are shown in Table 1. We found that AFP, CA125 and CA199 were differential expressed before and after SBRT. 
Then, we wanted to figure out the relationship between these markers and the overall survival (OS) for 1-year, 2-year, and 3-year (Table 2). From Table 2, significant differences were found between the survival group and the death group, i.e., change ratio of AFP in 6 months after SBRT, and CA125 in 3 months and 6 months after SBRT in 1-year, 2-year and 3-year OS. And no difference was found between the survival group and the death group in the change of CA199.

The diagnostic ability of these markers were then evaluated. The ROC curve was made and the sensitivity, specificity, AUC (Area Under the ROC Curve), Youden index and cut-off values were shown in Table 3. The Yoden index of AFP, CA125 and CA199 as prognostic markers for judging the efficacy of SBRT was less than 0.5. In addition, the AUC values of the change ratio of tumor biomarkers distinguishing survival group and death group were almost less than 0.70, except for CA125 in 6 months which were 0.781 and 0.715 in 1-year group and 2-year group, respectively, indicating that these commonly-used biomarkers do not provide a good assessment of the therapeutic efficacy of SBRT. Therefore, it is necessary to find more effective biomarkers for accurate assessment of the efficacy of SBRT in patients with liver cancer.

\section{High-throughput sequencing for gene profiles}

By the high-throughput sequencing, we obtained gene expression profiles before and after SBRT. Then, we compared the changes in gene expression before discharge (group 2) with pre-treatment (group 1), 2 months after SBRT treatment (group 3) with pre-treatment (group 1), and also group 3 vs group 2. Genes with $P<0.05$ were used as the differential gene, and the FPKM values of all differential genes in each comparison group were summarized. $\log _{2} \mathrm{FC}>0$ ( $\mathrm{FC}$ : fold change) was considered to be up-regulated, and $\log _{2} \mathrm{FC}<0$ was considered to be down-regulated, the visualization of the heatmap of the liver cancer samples are shown in Supplementary Fig. 1. In addition, due to the excessive number of differentially expressed genes, we limited the criteria for differential genes. By using $q<0.05$ ( $q$ value is adjusted $p$ value) and $\left|\log _{2} \mathrm{FC}\right|>1$ as screening criteria, differentially expressed genes were found out. Then, we listed all the differentially expressed genes of group 2 vs 1 , group 3 vs 1 and group 3 vs 2, it was found that a total of 16 differentially expressed genes remained elevated in all liver cancer patients after SBRT (i.e., upregulated in group 2 vs 1 and in group 3 vs 1, but no difference in group 3 vs 2) (shown in Supplementary Fig.2A). In addition, a total of 12 differentially expressed genes remained downregulation in all liver cancers after SBRT (i.e. down-regulated in group 2 vs 1 and in group 3 vs 1 , but no difference in group 3 vs 2) (shown in Supplementary Fig.2B).

\section{Evaluation of the differential genes for SBRT efficacy in liver cancer}

The expression of the above 28 genes were further verified by qPCR, which are shown in Supplementary Fig. 3 A-C. Nonparametric test was used to determine whether there were differences in gene expression before and after SBRT. We found that 21 genes were differently expressed, the detailed results are shown in Table 4.

Furtherly, we calculated the changes of 21 genes and evaluated whether the change in group 2 vs 1 , group 3 vs 1 were different between the effective and ineffective groups after SBRT. According to the imaging data of liver cancer patients, the therapeutic effects were divided into CR, PR, SD and PD based on the change of the diameter of liver cancer, CR and PR were classified into effective group, and SD and PD were classified into ineffective group. The results are shown in Table 5, it can be seen that ADIPOR1 and EPB42 were differentially expressed in pre-discharge versus before SBRT $(P<0.05)$, indicating that ADIPOR1 and EPB42 had significant changes in the short term after SBRT treatment. Therefore, in the following study, we mainly focused on the two genes ADIPOR1 and EPB42.

Since there was no significant difference in group 3 vs 1, we only evaluated the prognostic value of the change ratio of group 2 vs 1 in the efficacy of 3-month after SBRT for liver cancer. The evaluation results of the prognostic value for ADIPOR1 and EPB42 were listed in Table 6 and the ROC curves were shown in Supplementary Fig.4A-B. The results showed that ADIPOR1 had a sensitivity of $100 \%$ and a specificity of $83.33 \%$, at the optimal threshold of 0.5838 . And EPB42 had a sensitivity of $75 \%$ and a specificity of $100 \%$, at the optimal threshold of 1.3817 . Combined Table 5 with Table 6, it can be seen that when the change ratio of ADIPOR1 was lower than 0.5838 in pre-discharge compared with that before SBRT, patients had a better prognosis. Similarly, when the change of EPB42 was lower than 1.3817 in pre-discharge compared with that before SBRT, patients had a better prognosis after SBRT.

\section{Discussion}

In the current study, we mainly focused on evaluating the prognostic value of serum biomarkers, both the commonly used and novel biomarkers, for liver cancer patients treated by SBRT. Previous study reported that high AFP were associated with worse survival for liver patients who receiving Cyberknife treatment [15], however, all patients they included are in advanced or terminal stage of liver cancer. In our study, we evaluated the prognostic values of those existing tumor biomarkers, and found that those widely used tumor biomarkers such as AFP, CEA, CA199, etc. could not precisely predict the outcome of liver cancer treated by SBRT due to insufficient sensitivity or specificity, the Yoden index was less than 0.5 . Actually, although AFP is a well-known biomarker, the use of AFP as a screening indicator for liver cancer has been cancelled by the 2010 American Association for the Study of Liver Diseases (AASLD) guidelines due to its low sensitivity[16]. So, it is necessary to find more effective biomarkers for accurate assessment of the efficacy of SBRT in patients with liver cancer. Since the development of liver cancer is accompanied by mRNA changes[17-19], whether the changes of mRNA in whole blood can indicate the prognosis remains to be studied. 
Therefore, in our research, we explored potential biomarkers in mRNA level for the immediate-early assessment of prognosis after SBRT in patients with liver cancer through high-throughput sequencing and PCR. By using strict screening criteria, we finally got 28 differentially expressed mRNAs that were commonly increased or decreased after SBRT. Of all the 28 mRNAs, we found that the change ratio of ADIPOR1 (Z=-2.304, $P=0.021)$ and EPB42 $(Z=-2.304, P=0.021)$ in group 2 vs 1 was significantly different between the effective and ineffective groups at 3 months after SBRT.

Adiponectin is a hormone produced by adipocytes, regulates metabolic processes. Adiponectin is known to bind 3 receptors: adiponectin receptor 1 (AdipoR1), adiponectin receptor 2 (AdipoR2), and T-cadherin[20]. Previous studies revealed that the expression of ADIPOR1 was significantly lower in liver cancer than non-neoplastic hepatic tissues[21], and low expression of ADIPOR1was associated with increased risk of recurrence and death in patients with liver cancer[22]. While the evidence suggests an inverse relation of ADIPOR1 to malignancy, another study pointed out that increase of ADIPOR1 correlated with cancer progression. Patients who had chronic hepatitis $C$ with high serum adiponectin levels had a higher risk of liver cancer development [23]. In our study, ADIPOR1 is elevated after SBRT and had a good sensitivity and specificity in assessing the efficacy of SBRT after 3 months. Similarly, EPB42 (Erythrocyte membrane protein band 4.2) was also found to be a good prognostic biomarker for liver cancer treatment by SBRT. Furthermore, when the change of ADIPOR1 was lower than 0.5838 in pre-discharge compared with that before SBRT, patients had a better prognosis; when the change of EPB42 was lower than 1.3817 in pre-discharge compared with that before SBRT, patients had a better prognosis. In addition, routine blood-collection before treatment and before discharge, could not increase burden for patients, it is not only convenient to monitor the changes of ADIPOR1 or EPB42 and help to estimate whether the patient has a good prognosis, whether the patient needs further radiotherapy, consequently providing a reliable reference for the determination of the overall clinical treatment plan.

Although ADIPOR1 or EPB42 shown promising prognostic value for SBRT, it is still need more samples and further validation. In addition, how does ionizing radiation cause changes in ADIPOR1 and EPB42, and what's the underlying mechanism, remain to be studied.

\section{Declarations}

\section{Ethical Approval and Consent to participate}

The study design was approved by the Ethics Committee of the certain hospitals.

\section{Consent for publication}

The authors agree to publication.

\section{Availability of data and material}

The data used and analyzed in this study are available from the corresponding author upon request.

\section{Competing interests}

The authors declare that they have no competing interests in regard to this study.

\section{Acknowledgements}

This study was supported by The National Key Research and Development Program of

China囚2017YFC0108602\and NSFC of China $(81573082,81673092,81773363$, and 81872558).

\section{Abbreviations}

SBRT: Stereotactic body radiotherapy, CR: complete response, PR: partial response, SD: stable disease, PD: progressive disease, OS: overall survival, DFS: disease-free survival, PFS: progression-free survival, EBRT: external beam radiation therapy, BED: Biologically Effective Dose, ROC: receiver-operating characteristic curve; AUC: Area under ROC

\section{References}

1. Bray F, Ferlay J, Soerjomataram I, Siegel RL, Torre LA, Jemal A: Global cancer statistics 2018: GLOBOCAN estimates of incidence and mortality worldwide for 36 cancers in 185 countries. CA: a cancer journal for clinicians 2018, 68(6):394-424.

2. Chen W, Sun K, Zheng R, Zeng H, Zhang S, Xia C, Yang Z, Li H, Zou X, He J: Cancer incidence and mortality in China, 2014. Chinese journal of cancer research = Chung-kuo yen cheng yen chiu 2018, 30(1):1-12.

3. Zeng H, Zheng R, Guo Y, Zhang S, Zou X, Wang N, Zhang L, Tang J, Chen J, Wei K et al: Cancer survival in China, 2003-2005: a populationbased study. International journal of cancer 2015, 136(8):1921-1930.

4. Visvader JE: Cells of origin in cancer. Nature 2011, 469(7330):314-322. 
5. Zhang HH, Zhang Y, Cheng YN, Gong FL, Cao ZQ, Yu LG, Guo XL: Metformin incombination with curcumin inhibits the growth, metastasis, and angiogenesis of hepatocellular carcinoma in vitro and in vivo. 2018, 57(1):44-56.

6. Kim M, Kay CS, Jang WI, Kim MS, Lee DS, Jang HS: Prognostic value of tumor volume and radiation dose in moderate-sized hepatocellular carcinoma: A multicenter analysis in Korea (KROG 14-17). Medicine 2017, 96(24):e7202.

7. Klein J, Dawson LA: Hepatocellular carcinoma radiation therapy: review of evidence and future opportunities. International journal of radiation oncology, biology, physics 2013, 87(1):22-32.

8. NCCN clinical practice guidelines in oneology. Hepatobiliary cancers

9. Lazarev S, Hardy-Abeloos C, Factor O, Rosenzweig K, Buckstein M: Stereotactic body radiation therapy for centrally located hepatocellular carcinoma: outcomes and toxicities. Journal of cancer research and clinical oncology 2018, 144(10):2077-2083.

10. Murray LJ, Dawson LA: Advances in Stereotactic Body Radiation Therapy for Hepatocellular Carcinoma. Seminars in radiation oncology 2017, 27(3):247-255

11. Moon DH, Wang AZ, Tepper JE: A prospective study of the safety and efficacy of liver stereotactic body radiotherapy in patients with and without prior liver-directed therapy. Radiotherapy and oncology : journal of the European Society for Therapeutic Radiology and Oncology 2018, 126(3):527-533.

12. Jing W, Gao S, Zhu M, Luo P, Jing X, Chai H, Tu J: Potential diagnostic value of IncRNA SPRY4-IT1 in hepatocellular carcinoma. Oncology reports 2016, 36(2):1085-1092.

13. Jung J, Yoon SM, Han S, Shim JH, Kim KM, Lim YS, Lee HC, Kim SY, Park JH, Kim JH: Alpha-fetoprotein normalization as a prognostic surrogate in small hepatocellular carcinoma after stereotactic body radiotherapy: a propensity score matching analysis. BMC cancer 2015 , 15:987.

14. Uemoto K, Doi H, Shiomi H, Yamada K, Tatsumi D, Yasumoto T, Takashina M, Koizumi M, Oh RJ: Clinical Assessment of Micro-residual Tumors during Stereotactic Body Radiation Therapy for Hepatocellular Carcinoma. Anticancer research 2018, 38(2):945-954.

15. Kato H, Yoshida H, Taniguch H, Nomura R, Sato K, Suzuki I, Nakata R: Cyberknife treatment for advanced or terminal stage hepatocellular carcinoma. World journal of gastroenterology 2015, 21(46):13101-13112.

16. Bruix J, Sherman M: Management of hepatocellular carcinoma: an update. Hepatology (Baltimore, Md) 2011, 53(3):1020-1022.

17. Chen Y, Zhao J, Jiao Z, Wang W, Wang D, Yu X, Shi Z, Ge N, Pan Q, Xia J et al: SKA1 overexpression is associated with poor prognosis in hepatocellular carcinoma. BMC cancer 2018, 18(1):1240.

18. Wu D, Yang X, Peng H, Guo D, Zhao W, Zhao C, Zhou X: OCIAD2 suppressed tumor growth and invasion via AKT pathway in Hepatocelluar carcinoma. Carcinogenesis 2017, 38(9):910-919.

19. Hong JT, Son DJ, Lee CK, Yoon DY, Lee DH, Park MH: Interleukin 32, inflammation and cancer. Pharmacology \& therapeutics 2017, 174:127137.

20. Bloemer J, Pinky PD: Role of Adiponectin in Central Nervous System Disorders. 2018, 2018:4593530.

21. Hebbard L, Ranscht B: Multifaceted roles of adiponectin in cancer. Best practice \& research Clinical endocrinology \& metabolism 2014, 28(1):59-69.

22. Shin E, Yu YD, Kim DS, Won NH: Adiponectin receptor expression predicts favorable prognosis in cases of hepatocellular carcinoma. Pathology oncology research : POR 2014, 20(3):667-675.

23. Arano T, Nakagawa H, Tateishi R, Ikeda H, Uchino K, Enooku K, Goto E, Masuzaki R, Asaoka Y, Kondo Y et al: Serum level of adiponectin and the risk of liver cancer development in chronic hepatitis C patients. International journal of cancer 2011, 129(9):2226-2235.

\section{Tables}

Table 1. Analysis of the difference in the expression of tumor markers in patients before treatment, 3 months after treatment and 6 months after treatment 


\begin{tabular}{|c|c|c|c|c|c|c|c|c|c|c|}
\hline \multirow{2}{*}{$\begin{array}{c}\text { Tumor } \\
\text { biomarker }\end{array}$} & \multicolumn{5}{|c|}{3 months after SBRT vs before treatment } & \multicolumn{5}{|c|}{6 months after SBRT vs before treatment } \\
\hline & Number* & $\begin{array}{c}\text { Median level in } 3 \\
\text { months after } \\
\text { SBRT }\end{array}$ & $\begin{array}{c}\text { Median level } \\
\text { before } \\
\text { treatment }\end{array}$ & $\mathrm{Z}$ & $P$ & Number* & $\begin{array}{c}\text { Median level in } 6 \\
\text { months after } \\
\text { SBRT }\end{array}$ & $\begin{array}{c}\text { Median level } \\
\text { Before } \\
\text { treatment }\end{array}$ & $\mathrm{Z}$ & $P$ \\
\hline AFP & 367 & $18.00(5.92,182.20)$ & $\begin{array}{l}103.10 \\
(7.86,1210.00)\end{array}$ & -8.312 & 0.000 & 233 & $11.62(4.58,128.85)$ & $\begin{array}{l}52.51 \\
(6.52,1176.00)\end{array}$ & -6.141 & 0.000 \\
\hline CEA & 309 & $2.65(1.77,4.21)$ & $2.73(1.63,4.55)$ & -0.888 & 0.375 & 204 & $2.83(1.85,3.98)$ & $2.86(1.65,4.31)$ & -0.363 & 0.716 \\
\hline CA125 & 295 & $20.95(14.06,59.95)$ & $18.91(10.72,44.12)$ & -2.997 & 0.003 & 197 & $\begin{array}{l}21.24(12.42, \\
62.92)\end{array}$ & $\begin{array}{l}\text { 16.56(9.80, } \\
34.73)\end{array}$ & -4.067 & 0.000 \\
\hline CA153 & 281 & $15.00(10.58,21.68)$ & $14.57(10.22,21.29)$ & -0.540 & 0.589 & 193 & $13.38(9.33,20.40)$ & $\begin{array}{l}13.59(9.74 \\
20.00)\end{array}$ & -0.270 & 0.787 \\
\hline CA199 & 303 & $27.24(13.17,48.53)$ & $26.40(12.01,50.74)$ & -0.316 & 0.752 & 202 & $21.71(8.27,44.24)$ & $\begin{array}{l}\text { 25.93(9.22, } \\
50.05)\end{array}$ & -2.551 & 0.011 \\
\hline CA724 & 285 & $1.42(1.05,2.63)$ & $1.30(0.98,2.89)$ & -1.278 & 0.201 & 193 & $1.47(1.05,2.69)$ & $\begin{array}{l}1.28(0.99 \\
2.72)\end{array}$ & -1.204 & 0.229 \\
\hline
\end{tabular}

* means the number of patients with an expression record before SBRT and 3 or 6 months after SBRT.

Table. 2 Analysis of the difference in the proportion of tumor markers in the survival group and the death group

\begin{tabular}{|c|c|c|c|c|c|c|c|}
\hline $\begin{array}{l}\text { Follow up } \\
\text { time }\end{array}$ & $\begin{array}{c}\text { Proportion of tumor } \\
\text { markers }\end{array}$ & $\begin{array}{l}\text { Survive } \\
\text { number }\end{array}$ & $\begin{array}{l}\text { Death } \\
\text { number }\end{array}$ & $\begin{array}{l}\text { proportion of tumor markers in } \\
\text { survival group } \\
\mathrm{M}\left(\mathrm{P}_{25}, \mathrm{P}_{75}\right)\end{array}$ & $\begin{array}{c}\text { proportion of tumor markers in } \\
\text { death group } \\
\mathrm{M}\left(\mathrm{P}_{25}, \mathrm{P}_{75}\right)\end{array}$ & $\bar{Z}$ & $\bar{P}$ \\
\hline \multirow[t]{5}{*}{ One-year } & $\begin{array}{c}\text { AFP } 3 \text { months vs } \\
\text { before }\end{array}$ & 161 & 65 & $-0.318(-0.873,0.276)$ & $0.000(-0.557,0.458)$ & -1.808 & 0.071 \\
\hline & $\begin{array}{c}\text { AFP } 6 \text { months vs } \\
\text { before }\end{array}$ & 130 & 26 & $-0.380(-0.908,0.216)$ & $0.000(-0.474,0.860)$ & -2.264 & 0.024 \\
\hline & $\begin{array}{c}\text { CA125 } 3 \text { months vs } \\
\text { before }\end{array}$ & 123 & 49 & $0.085(-0.325,0.580)$ & $0.651(-0.217,2.083)$ & -3.019 & 0.003 \\
\hline & $\begin{array}{c}\text { CA125 } 6 \text { months vs } \\
\text { before }\end{array}$ & 106 & 21 & 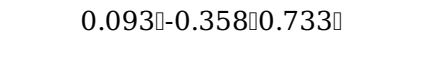 & $2.583(0.540,13.327)$ & -4.056 & 0.000 \\
\hline & $\begin{array}{c}\text { CA199 } 6 \text { months vs } \\
\text { before }\end{array}$ & 108 & 22 & $-0.063(-0.367,0.165)$ & $0.333(-0.172,2.472)$ & -2.791 & 0.005 \\
\hline \multirow[t]{5}{*}{ Two-year } & $\begin{array}{c}\text { AFP } 3 \text { months vs } \\
\text { before }\end{array}$ & 78 & 96 & $-0.446(-0.909,0.272)$ & $0.000(-0.593,0.471)$ & -2.313 & 0.021 \\
\hline & $\begin{array}{l}\text { AFP } 6 \text { months vs } \\
\text { before }\end{array}$ & 65 & 51 & $-0.710(-0.928,0.268)$ & $0.000(-0.571,0.716)$ & -2.934 & 0.003 \\
\hline & $\begin{array}{c}\text { CA125 } 3 \text { months vs } \\
\text { before }\end{array}$ & 59 & 71 & $0.051(-0.196,0.459)$ & $0.625(-0.273,1.991)$ & -2.864 & 0.004 \\
\hline & $\begin{array}{l}\text { CA125 } 6 \text { months vs } \\
\text { before }\end{array}$ & 53 & 39 & $-0.019(-0.451,0.487)$ & $0.959(-0.033,5.315)$ & -3.504 & 0.000 \\
\hline & $\begin{array}{c}\text { CA199 } 6 \text { months vs } \\
\text { before }\end{array}$ & 56 & 40 & $-0.063(-0.360,0.164)$ & $0.092(-1.312,1.519)$ & -2.389 & 0.017 \\
\hline \multirow[t]{5}{*}{$\begin{array}{l}\text { Three- } \\
\text { year }\end{array}$} & $\begin{array}{c}\text { AFP } 3 \text { months vs } \\
\text { before }\end{array}$ & 33 & 100 & $-0.349(-0.871,0.468)$ & $0.000(-0.635,0.487)$ & -1.188 & 0.235 \\
\hline & $\begin{array}{l}\text { AFP } 6 \text { months vs } \\
\text { before }\end{array}$ & 26 & 59 & $-0.750(-0.939,0.609)$ & $0.000(-0.574,0.716)$ & -2.055 & 0.040 \\
\hline & $\begin{array}{c}\text { CA125 } 3 \text { months vs } \\
\text { before }\end{array}$ & 27 & 77 & $0.108(-0.316,0.489)$ & $0.651(-0.252,1.787)$ & -2.324 & 0.020 \\
\hline & $\begin{array}{c}\text { CA125 } 6 \text { months vs } \\
\text { before }\end{array}$ & 21 & 46 & $0.029(-0.348,0.824)$ & $0.851(-0.107,4.753)$ & -2.365 & 0.018 \\
\hline & $\begin{array}{c}\text { CA199 } 6 \text { months vs } \\
\text { before }\end{array}$ & 22 & 47 & $0.045(-0.168,0.305)$ & $0.091(-0.308,0.761)$ & -0.773 & 0.440 \\
\hline
\end{tabular}

Table. 3 Evaluation of predictive efficacy in distinguishing survival group and death group of the tumor markers 


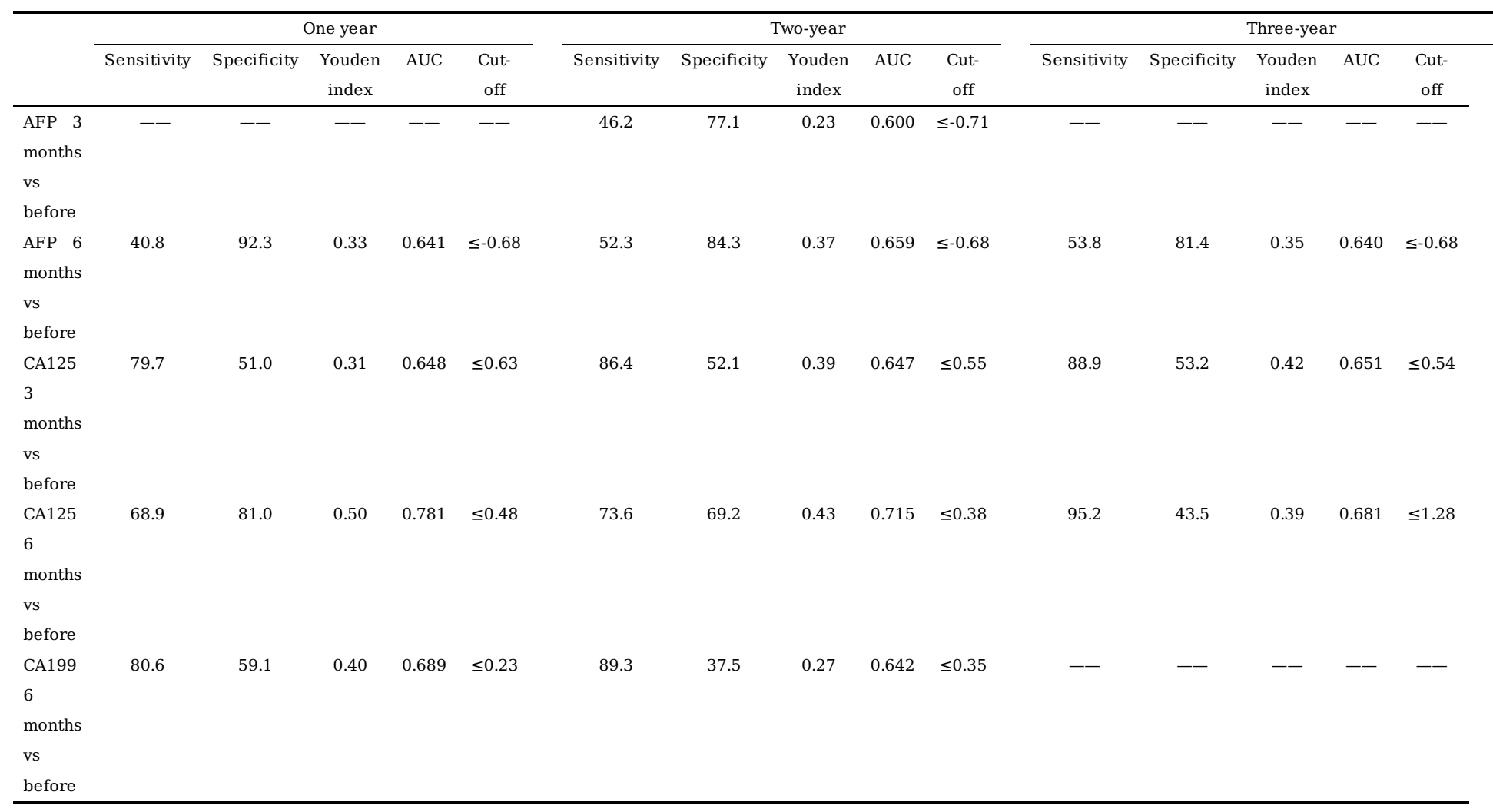

AUC: Area under receiver-operating characteristic (ROC) curve.

Table 4. Gene expression levels before and after SBRT treatment

\begin{tabular}{|c|c|c|c|c|c|c|c|c|}
\hline Gene & $\begin{array}{l}\text { before discharge } \\
\mathrm{M}\left(\mathrm{P}_{25}, \mathrm{P}_{75}\right)\end{array}$ & $\begin{array}{l}\text { before SBRT } \\
M\left(\mathrm{P}_{25}, \mathrm{P}_{75}\right)\end{array}$ & $Z$ & $P$ & $\begin{array}{c}2 \text { months after SBRT M }\left(\mathrm{P}_{25}\right. \\
\left.\mathrm{P}_{75}\right)\end{array}$ & $\begin{array}{l}\text { before SBRT } \\
\mathrm{M}\left(\mathrm{P}_{25}, \mathrm{P}_{75}\right)\end{array}$ & $Z$ & $P$ \\
\hline ADIPOR1 & $1.337(0.685,2.419)$ & $0.880(0.572,2.630)$ & -2.722 & 0.006 & $2.245(0.931,349.816)$ & $\begin{array}{r}1.059(0.606 \\
159.744)\end{array}$ & -2.040 & 0.041 \\
\hline ANK1 & $0.003(0.001,0.006)$ & $0.004(0.001,0.010)$ & -0.166 & 0.868 & $0.004(0.001,3.542)$ & $0.004(0.001,0.013)$ & -0.784 & 0.433 \\
\hline ASCC2 & $0.042(0.015,0.057)$ & $0.03(0.015,0.066)$ & -1.207 & 0.227 & $0.047(0.019,1.012)$ & $0.072(0.019,2.103)$ & -2.275 & 0.023 \\
\hline BCAM & $0.000(0.000,0.002)$ & $0.000(0.000,0.002)$ & -1.065 & 0.287 & $0.001(0.001,1.040)$ & $0.000(0.000,0.003)$ & -1.647 & 0.099 \\
\hline BCL11B & $0.004(0.003,0.011)$ & $0.009(0.006,0.024)$ & -3.195 & 0.001 & $0.015(0.011,0.787)$ & $0.011(0.006,2.129)$ & -0.471 & 0.638 \\
\hline BCL2L1 & $0.503(0.271,0.965)$ & $0.581(0.237,1.207)$ & -1.965 & 0.049 & $0.731(0.303,35.545)$ & $\begin{array}{r}0.738(0.334 \\
15.770)\end{array}$ & -1.334 & 0.182 \\
\hline BLK & $0.001(0001,0.016)$ & $0.003(0.002,0.010)$ & -2.296 & 0.022 & $0.004(0.001,0.206)$ & $0.003(0.002,1.517)$ & -1.647 & 0.099 \\
\hline BTLA & $0.029(0.017,0.079)$ & $0.045(0.023,0.082)$ & -1.586 & 0.113 & $0.060(0.024,0.880)$ & $0.044(0.023,3.730)$ & -0.941 & 0.347 \\
\hline CAT & $0.117(0.074,0.220)$ & $0.154(0.104,0.304)$ & -2.817 & 0.005 & $0.204(0.133,3.892)$ & $0.175(0.116,7.493)$ & -1.098 & 0.272 \\
\hline CD79A & $0.016(0.010,0.050)$ & $0.046(0.025,0.118)$ & -3.575 & 0.000 & $0.053(0.012,3.221)$ & $0.068(0.028,7.370)$ & -1.962 & 0.050 \\
\hline COL19A & $0.004(0.001,0.021)$ & $0.013(0.006,0.087)$ & -3.243 & 0.001 & $0.013(0.002,0.097)$ & $0.013(0.004,1.018)$ & -1.412 & 0.158 \\
\hline CXCR5 & $0.001(0.000,0.003)$ & $0.003(0.001,0.004)$ & -3.527 & 0.000 & $0.002(0.000,0.175)$ & $0.003(0.002,1.550)$ & -1.726 & 0.084 \\
\hline EPB42 & $0.039(0.015,0.068)$ & $0.027(0.011,0.054)$ & -2.817 & 0.005 & $0.058(0.021,3.540)$ & $0.026(0.011,1.543)$ & -3.059 & 0.002 \\
\hline GOLGA6L9 & $0.001(0.00$ & $0.002(0.000,0.006)$ & -2.154 & 0.031 & $0.003(0.000,0.052)$ & $0.004(0.001,0.316)$ & -2.197 & 0.028 \\
\hline IL7R & $0.176(0.113,0.602)$ & $0.492(0.292,1.024)$ & -3.385 & 0.001 & $0.536(0.265,17.622)$ & $\begin{array}{r}0.665(0.274, \\
53.358)\end{array}$ & -1.726 & 0.084 \\
\hline KLHL14 & 0.00 & 7) & -3.385 & .001 & 49) & $0.002(0.000,1.031)$ & -2.118 & 0.034 \\
\hline MAP2K3 & $0.053(0.027,0.085)$ & $0.044(0.029,0.088)$ & -1.538 & 0.124 & $0.060(0.024,57.292)$ & $0.070(0.031,7.327)$ & -1.020 & 0.308 \\
\hline OR2W3 & $0.008(0.004,0.020)$ & $0.008(0.003,0.017)$ & -1.349 & 0.177 & $0.010(0.007,29.623)$ & $0.010(0.004,9.895)$ & -2.353 & 0.019 \\
\hline OSBP2 & $0.000(0.000,0.001)$ & $0.000(0.000,0.001)$ & -1.870 & 0.061 & $00,9.563)$ & $0.000(0.000,4.499)$ & -1.256 & 0.209 \\
\hline PAX5 & $0.001(0.000,0.003)$ & $.003,0.006)$ & -3.479 & 0.001 & $1,0.279)$ & $0.004(0.002,1.416)$ & -2.197 & 0.028 \\
\hline FECH & $0.396(0.178,0.732)$ & $0.355(0.159,0.655)$ & -1.728 & 0.084 & $0.597(0.440,2.363)$ & $0.468(0.223,0.997)$ & -2.197 & 0.028 \\
\hline PIM1 & $0.241(0.160,0.435)$ & $0.176(0.073,0.398)$ & -1.870 & 0.062 & $0.397(0.149,1.296)$ & $0.242(0.065,0.493)$ & -1.334 & 0.182 \\
\hline SFRP2 & $0.002(0.001,0.007)$ & $0.002(0.001,0.007)$ & -2.107 & 0.035 & $0.002(0.001,0.821)$ & $0.003(0.001,0.215)$ & -1.020 & 0.308 \\
\hline STAP1 & $0.005(0.002,0.014)$ & $0.016(0.007,0.030)$ & -3.574 & 0.000 & $0.016(0.006,0.156)$ & $0.019(0.007,1.553)$ & -1.647 & 0.099 \\
\hline TMCC2 & $0.025(0.014,0.080)$ & $0.014(0.010,0.116)$ & -2.249 & 0.025 & $0.044(0.018,7.788)$ & $0.025(0.011,1.927)$ & -1.961 & 0.050 \\
\hline UBA52 & 6.383(4.086, & 5.160 (3.247, & -0.970 & 0.332 & $12.730(7.651,173.134)$ & 6.438(3.963, & & \\
\hline & & & & & & & -2.118 & 0.034 \\
\hline UBB & $\begin{array}{r}9.989(3.795 \\
13.428)\end{array}$ & $4.941(2.943,8.312)$ & -1.49 & 0.13 & $9.453(7.354,19.715)$ & $937(3.143,8.559)$ & -2.2 & 0.023 \\
\hline YBX1 & $0.866(0.531,1.797)$ & $1.188(0.452,1.936)$ & -0.876 & 0.381 & $1.865(0.529,12.223)$ & $1.348(0.714,4.095)$ & -1.412 & 0.158 \\
\hline
\end{tabular}


Table 5. Change ratio of differentially expressed genes in the effective and ineffective groups of liver cancer at 3 months after SBRT

\begin{tabular}{|c|c|c|c|c|c|c|c|c|}
\hline \multirow[t]{2}{*}{$\begin{array}{l}\text { Differential } \\
\text { gene }\end{array}$} & \multicolumn{4}{|c|}{$\begin{array}{l}\text { Change ratio of the expression before discharge and } \\
\text { before SBRT } \\
(2 \mathrm{vs} 1)\end{array}$} & \multicolumn{4}{|c|}{$\begin{array}{l}\text { Change ratio of the expression in } 2 \text { months after SBRT and before } \\
\text { SBRT (3vs1) }\end{array}$} \\
\hline & Effective & Ineffective & $Z$ & $P$ & Effective & Ineffective & $Z$ & $P$ \\
\hline ADIPOR1 & $\begin{array}{r}0.205(-0.112, \\
0.571)\end{array}$ & $1.020(0.874,1.484)$ & -2.304 & 0.021 & $0.464(-0.098,1.400)$ & $1.298(0.281,--)$ & -1.202 & 0.229 \\
\hline ASCC2 & $\begin{array}{r}0.149(-0.218 \\
0.479)\end{array}$ & $\begin{array}{r}0.675(-0.034 \\
1.591)\end{array}$ & -1.455 & 0.146 & $0.376(-0.080,1.503)$ & $0.315(0.276,--)$ & -0.277 & 0.782 \\
\hline BCL11B & $\begin{array}{r}-0.514(-0.820 \\
-0.127)\end{array}$ & $\begin{array}{r}-0.523(-0.706 \\
-0.508)\end{array}$ & -0.364 & 0.716 & $0.670(-0.591,1.578)$ & $-0.473(-0.898,--)$ & -1.387 & 0.166 \\
\hline BCL2L1 & $0.307(0.039,0.865)$ & $\begin{array}{r}0.196(-0.285 \\
0.989)\end{array}$ & -0.364 & 0.716 & $0.546(0.005,1.502)$ & $-0.342(-0.619,--)$ & -0.647 & 0.518 \\
\hline BLK & $\begin{array}{r}-0.512(-0.864 \\
0.024)\end{array}$ & $\begin{array}{r}-0.496(-0.847 \\
-0.325)\end{array}$ & -0.485 & 0.628 & $-0.523(-0.842,1.522)$ & $-0.433(-0.926,--)$ & -0.277 & 0.782 \\
\hline CAT & $\begin{array}{r}-0.454(-0.624 \\
0.040)\end{array}$ & $\begin{array}{r}-0.176(-0.669 \\
0.194)\end{array}$ & -0.485 & 0.628 & $-0.369(-0.509,0.630)$ & $0.310(-0.740,--)$ & -0.277 & 0.782 \\
\hline CD79A & $\begin{array}{r}-0.817(-0.892 \\
-0.507)\end{array}$ & $\begin{array}{r}-0.592(-0.849 \\
-0.306)\end{array}$ & -0.789 & 0.430 & $-0.564(-0.662,0.408)$ & $-0.564(-0.680,--)$ & -0.185 & 0.853 \\
\hline COL19A & $\begin{array}{r}-0.823(-0.918 \\
-0.354)\end{array}$ & $\begin{array}{r}-0.384(-0.889 \\
0.030)\end{array}$ & -0.606 & 0.544 & $-0.608(-0.853,0.685)$ & $-0.221(-0.933,--)$ & -0.092 & 0.926 \\
\hline CXCR5 & $\begin{array}{r}-0.628(-0.876 \\
-0.357)\end{array}$ & $\begin{array}{r}-0.594(-0.900 \\
-0.080)\end{array}$ & -0.121 & 0.903 & $-0.495(-($ & $-0.609(-0.912,--)$ & -0.647 & 0.518 \\
\hline EPB42 & $0.400(0.087,0.589)$ & $2.062(0.747,2.678)$ & -2.304 & 0.021 & $1.303(0$ & $1.616(1.538,--)$ & -1.757 & 0.079 \\
\hline GOLGA6L9 & $\begin{array}{r}-0.440(-0.811 \\
-0.088)\end{array}$ & $\begin{array}{r}-0.757(-0.869 \\
0.526)\end{array}$ & -0.728 & 0.467 & $-0.227(-0.656,0.093)$ & $-0.710(-0.860,--)$ & -1.757 & 0.079 \\
\hline IL7R & $\begin{array}{r}-0.721(-0.828 \\
-0.514)\end{array}$ & $\begin{array}{r}-0.595(-0.726 \\
-0.014)\end{array}$ & -1.213 & 0.225 & $-0.222(-0.672,0.955)$ & $-0.188(-0.673,0.266)$ & -0.092 & 0.926 \\
\hline KLHL14 & $\begin{array}{r}-0.846(-0.900 \\
-0.566)\end{array}$ & $\begin{array}{r}-0.103(-0.901 \\
1.542)\end{array}$ & -1.455 & 0.146 & $-0.535(-0.792,-0.003)$ & $-0.346(-0.955,1.576)$ & -0.462 & 0.644 \\
\hline OR2W3 & $\begin{array}{r}-0.041(-0.150 \\
1.198)\end{array}$ & $0.236(0.077,1.56)$ & -1.091 & 0.275 & $0.886(0.156,1.424)$ & $0.316(-0.364,2.293)$ & -0.462 & 0.644 \\
\hline PAX5 & $\begin{array}{r}-0.777(-0.927 \\
0.253)\end{array}$ & $\begin{array}{r}-0.894(-0.919 \\
-0.547)\end{array}$ & -0.243 & 0.808 & $-0.561(-0.855,0.088)$ & $-0.716(-0.888,-0.651)$ & -1.202 & 0.229 \\
\hline $\mathrm{FECH}$ & $\begin{array}{r}0.117(-0.175 \\
1.496)\end{array}$ & $0.496(0.218,1.053)$ & -0.970 & 0.332 & $0.693(0.146,1.630)$ & $0.313(-0.362,--)$ & -0.092 & 0.926 \\
\hline SFRP2 & $\begin{array}{r}0.408(-0.083 \\
1.400)\end{array}$ & $0.482(-0.03,3.984)$ & -0.849 & 0.396 & $0.178(-0.248,1.267)$ & $0.318(-0.629,1.702)$ & -0.277 & 0.782 \\
\hline STAP1 & $\begin{array}{r}-0.737(-0.862 \\
-0.539)\end{array}$ & $\begin{array}{r}-0.760(-0.918 \\
-0.469)\end{array}$ & -0.485 & 0.628 & $-0.344(-0.671,0.656)$ & $-0.406(-0.919,0.075)$ & -0.647 & 0.518 \\
\hline TMCC2 & $\begin{array}{r}0.407(-0.091 \\
0.615)\end{array}$ & $\begin{array}{r}0.961(-0.015 \\
1.467)\end{array}$ & -1.334 & 0.182 & $1.441(0.128,2.334)$ & $0.269(-0.257,1.577)$ & -0.832 & 0.405 \\
\hline UBA52 & $\begin{array}{r}-0.003(-0.281 \\
0.679)\end{array}$ & $0.124(-0.067,1.043)$ & -1.213 & 0.225 & $1.244(-0.096,1.829)$ & $0.307(0.03,2.915)$ & -0.092 & 0.926 \\
\hline UBB & $\begin{array}{r}-0.085(-0.238 \\
0.578)\end{array}$ & $0.591(0.51,2.296)$ & -1.940 & 0.052 & $1.135(0.014,2.219)$ & $1.295(0.36,2.302)$ & -0.462 & 0.644 \\
\hline
\end{tabular}

Table 6. The evaluation results of the prognostic value of the change ratio of ADIPOR1 and EPB42 (2vs1) for liver cancer patients in 3 months after SBRT

\begin{tabular}{|c|c|c|c|c|c|c|}
\hline \multirow[t]{2}{*}{ mRNA } & \multirow[t]{2}{*}{ AUC } & \multirow[t]{2}{*}{$\mathrm{SE}$} & Sensitivity & Specificity & \multirow[t]{2}{*}{ Yoden index } & \multirow[t]{2}{*}{ Cut-off } \\
\hline & & & $\square \% \square$ & प\%口 & & \\
\hline ADIPOR1 & 0.896 & 0.087 & 100 & 83.33 & 0.83 & 0.5838 \\
\hline EPB42 & 0.896 & 0.111 & 75.00 & 100.00 & 0.75 & 1.3817 \\
\hline
\end{tabular}

*2vs1, means pre-discharge versus before SBRT

\section{Supplementary Files}

This is a list of supplementary files associated with this preprint. Click to download.

- supplementalfigurelegends.docx

- figs1.PNG

- figs3.PNG

- figs2.PNG

- figs4.PNG 